Ali et al., 2009

\title{
Stamford Journal of
}

\section{Effect of raw materials on drug release from developed Ciprofloxacin tablets}

\author{
Heyam Saad Ali ${ }^{1{ }^{*}}$, Junaid Aslam ${ }^{3}$, Bazigah Rasool ${ }^{1}$, Saeed Ahemad \\ Khan $^{2}$, Alaa Agondi ${ }^{4}$ \\ Department of Pharmaceutics ${ }^{1}$, Department of Pharmaceutical and \\ Medicinal Chemistry ${ }^{2}$, Plant Tissue Culture Laboratory ${ }^{3}$, Dubai \\ Pharmacy College Al Muhasinah -1, Al Mizhar, Dubai, United Arab \\ Emirates, Quality Control ${ }^{4}$, Pharmaceutical Chemistry, Julvar, Ras \\ Alkhaima, United Arab Emirates.
}

\author{
*Corresponding Author \\ Dr. Heyam Saad Ali \\ Associate Professor \\ Department of Pharmaceutics \\ Dubai Pharmacy College \\ Al Muhasinah-1, Al Mizhar, \\ Dubai, United Arab Emirates \\ E-mail: hyam5@hotmail.com
}

\begin{abstract}
The present study was undertaken to assess and evaluate the effect of two parameters on tablet formulation of Ciprofloxacin: a) particle size of raw material and b) storage conditions of both raw material and finished product. The raw materials were two commercial products, coarse (RM1) and fine (RM2) and locally produced granular form (RM3) prepared from RM2. Three tablet formulations were prepared from the raw materials and designated as F1, F2 and F3. The formulation F1 were prepared from RM1, F2 from RM2 by slugging and $\mathrm{F} 3$ from RM3 by direct compression. The raw materials and finished products were then subjected to assessment of the different parameters at the time of production and after storage for three month. The particle size distribution for the raw materials was found to be $<100,100-250$ and $>250 \mu \mathrm{m}$ for RM2, RM1 and RM3, respectively. The moisture uptake at $25{ }^{\circ} \mathrm{C}$ and $4{ }^{\circ} \mathrm{C}$ under $75 \% \mathrm{RH}$ was found to be the highest for the fine powder raw material (RM2), however, the developed granular form RM3 showed the least uptake. Moreover, F2 did not attain $80 \%$ dissolution after storage of 3 month. The F1 and F3 formulation passed the dissolution test after storage of 3 month, hence, F3 showed the highest value of dissolution (82\%) in 30 minutes. The physicochemical properties of raw materials, storage conditions, and manufacturing techniques were found to exert a great influence over the dissolution behavior of Ciprofloxacin tablet formulations.
\end{abstract}

Key words: Ciprofloxacin tablets, dissolution behavior, physicochemical properties, storage conditions

\section{INTRODUCTION}

Ciprofloxacin is a synthetic antibacterial fluoroquinolone, it is related to nalidixic acid, however, the relative potency has been increased by a fluorine atom and a piperazine moiety; it plays a very potent role in the treatment of numbers of infections (Chantraine et al., 2007). Batch-to-batch variation in raw material properties and variation between lots obtained from different suppliers can lead to processing difficulties and variability in the properties of finished product. These, variability may be because of a change in raw material properties arising from modification in the raw material manufacturing process (Timmins, 1986; Lide, 2001). There are few reports on interbatch variation in active ingredients, and the effects of this variation on the subsequent product properties and performance. More subtle variability in materials can occur, resulting in problems for formulators. The changes in subtle process may have marked effects on active ingredients, as indicated by studies performed on ibuprofen (Timmins, 1986; Physician's Desk Reference, 2001). Mechanical property changes in ibuprofen compacts could be produced simply by alteration in the crystallization rate of raw material. Batch-to-batch variability in the particle size distribution and particle shape of the drug raw material can result a problems during compression. It has been shown that the variability in particle size of raw materials affects their compaction properties (Timmins, 1986). Granulation techniques may expect to overcome batch to batch variability in particle shape of drug and it is distribution. Keeping these views, the present study was undertaken to assess and evaluate the effect of two parameters (particle size of raw material and storage conditions of both raw material and finished product) .on Ciprofloxacin tablet formulation. 


\section{MATERIALS AND METHODS}

\section{Experimental material}

Ciprofloxacin hydrochloride $(\mathrm{HCl})$ pure powder was a gift from two different suppliers; RM1 (Fine AG, Germany); RM2 (Siegfried AG, Switzerland); PVP K-25 (ISP, Switzerland) as a wet granulation binder; Aerosil 200 fumed silica (Degussa AG, Germany) as a powder flow aid; Avicel PH102 microcrystalline cellulose (Lehmann and Voss and Co., Germany); and lactose monohydrate (DMV Campina BV, Holland) as fillers; talc powder (Tardy, France) and magnesium stearate (Union Deriva, Spain) as lubricants, Ac-Di-Sol Croscarmellose sodium (FMC International, Ireland) as a disintegrant, methanol as a mobile phase and 1-hexanesulfonic acid sodium salt (BDH Chemicals Ltd, UK) as ion-pairing agent, isopropanol (Sudanese Pharmaceuticals Co, Sudan) as solvent for PVP K-25.

\section{Development of RM3 from RM2}

Granulated raw material (RM3) was prepared in a Torrmat (Type FH-6; Drias, Germany) machine by kneading RM2 with a $2 \%$ w/v alcoholic solution of PVP K-25, followed by drying in a hot air oven at $60^{\circ} \mathrm{C}$ for $5 \mathrm{~min}$. The particle size of the wet granules was then reduced by passing through an oscillating granulator (Type F.G.S.; Erweka, Germany) fitted with a $1 \mathrm{~mm}$ sieve.

\section{Evaluation and testing of three Ciprofloxacin raw materials (RM1, RM2 and RM3)}

Materials were ground with Nujol mull and placed between two potassium bromide disks, and their infrared spectra were recorded using spectrophotometer (Cary 50 UV-Vis spectrophotometer, USA).

\section{Moisture content}

Moisture contents of raw material was determined by the Karl Fischer method as described in the USP 25 (The United States Pharmacopoeia, 2002).

\section{Moisture uptake}

Two grams of sample of each raw material were placed in open, previously weighed petri dishes, which were then put into desiccators containing a saturated solution of sodium chloride in purified water to give a relative humidity of about $75 \%$. The desiccators were stored at two different temperatures $25 \pm 1{ }^{\circ} \mathrm{C}$ and $40 \pm 1{ }^{\circ} \mathrm{C}$. These conditions were considered representative of storage in temperate and tropical regions. Petri dishes were then removed from the two desiccators at predetermined time intervals $(7,14,30,45,60$ and 90 days) and rapidly weighed. The weight gain, representing the amount of moisture absorbed, and the percentage moisture gain were calculated and plotted against time.

\section{Drug release tests of the three raw materials (dissolution test of raw material)}

The test was performed on $0.4 \mathrm{~g}$ samples of raw materials in a USP Apparatus II paddles (Pharma Test PTWS III, Germany) employing $900 \mathrm{~mL}$ of water $\mathrm{pH}$, at $37^{\circ} \mathrm{C}$ and $50 \mathrm{rpm} .5 \mathrm{~mL}$ dissolution media samples, replaced with fresh medium, were withdrawn at a predetermined time, filtered, diluted and assayed spectrophotometerically at $276 \mathrm{~nm}$ (The United States Pharmacopoeia, 2002).

\section{Particle properties assessment}

Particle size was measured using (Mastersizer 2000 particle size analyzer, malvern instrument UK).

\section{Flowability and compressibility assessment}

Hausner ratio (HR), Carr's compressibility index $(\mathrm{Cl} \%)$, and the angles of repose $\left({ }^{\circ}\right)$ are related to two rheological features of powders a) flowability and b) compressibility. Hausner ratio (HR) and Carr's compressibility index $(\mathrm{Cl} \%)$ are calculated according to the relation between tapped and bulk densities.

$$
\begin{aligned}
& \text { Hausner ratio }(H R)=\underline{P}_{1250} \\
& \text { Carr's compressibility index }(\% C)=\frac{P_{0}}{1250-P_{0}} \times 100 \\
& P_{1250}
\end{aligned}
$$




\section{Angle of repose ( $\left.{ }^{\circ}\right)$}

It was used as indirect method of quantifying powder flowability; this measurement was performed using $10 \mathrm{~g}$ of the powder in study and a funnel, it is measured from the cone formed by the powder falling by gravity with a vibrating system. It was measured using (Hosokawa PT-N® powder tester).

\section{Bulk density $(\rho 0)$}

$25 \mathrm{~g}$ of powder complex was poured into a glass measuring cylinder (SBS-model Vol-1) in (Hosokawa PT-N® powder tester) and measuring the initial volume occupied (V0).

\section{Tapped density ( 1250$)$}

The same cylinder with the powder was then automatically tapped 1250 times (constant volume) and measuring the final volume occupied.

\section{Tablet preparation}

The three tablet formulations (741 mg target weight) used in this study are shown in (Table 2). The compositions of the three developed tablets were kept as close as possible to allow reliable comparison of all formulations. Formulations F1 (fromRM1) and F2 (from RM2) were prepared by slugging using tablet machine (Type AR400, Erweka GmbH, Germany) and $25 \mathrm{~mm}$ punches. The obtained slugs were crushed in an oscillating granulator (Type FGS, Erweka, Germany) fitted with $1 \mathrm{~mm}$ sieve, mixed with other additives in a double-cone mixer (Type DKM, Erweka) and finally compressed. F3 (from RM3) tablets were prepared by direct compression after mixing of all ingredients for $10 \mathrm{~min}$ followed by another $5 \mathrm{~min}$ after adding the lubricants in a double-cone mixer. All tablets were prepared using $11 \mathrm{~mm}$ concave punches.

\section{TESTING OF THE PREPARED TABLETS}

\section{Friability test}

It was performed on 10 weighed tablets using a Pharma Test machine (Type TAD, Erweka GmbH, Germany) at a fixed speed (25 rpm) for $15 \mathrm{~min}$ (The United States Pharmacopoeia, 2002).

\section{Disintegration test}

Six tablets were used in the test according to the specifications of USP 25 disintegration test for plain tablets using (Disintegration Tester, Pharma Test Type PTz Auto.4EZSN, and Germany) and water maintained at $37 \pm 2{ }^{\circ} \mathrm{C} .5$ until no particle remained on the basket of the system. The time taken for each of the three tested tablets was recorded (The United States Pharmacopoeia, 2002).

\section{Dissolution test}

It was performed according to USP 25 monograph for Ciprofloxacin tablets (The United States Pharmacopoeia, 2002).

\section{Hardness test}

This test was applied with a hardness tester (Multi check Pharma Test, Germany) on 10 tablets for each Ciprofloxacin formulation.

\section{Stability test}

The tablets prepared from the three formulations were stored in unstoppered plastic bottles away from light and under each of the following conditions a) room temperature $25{ }^{\circ} \mathrm{C}$ and $75 \%$ relative humidity $(\mathrm{RH})$ b) room temperature $40{ }^{\circ} \mathrm{C}$ and $75 \% \mathrm{RH}$. The tablets were tested after $1,2,3$ months of storage, and any change in physical appearance, dissolution rate and moisture uptake were detected.The integrity of ciprofloxacin in ciprofloxacin tablet was performed using HPLC unit (equipped with, Perkin Elmer Autosampler 200 series, Perkin Elmer pump 200 series, Perkin Elmer DAD Detector 200 series, and total Chromatography software Integration system).

\section{RESULTS AND DISCUSSION}

The infrared spectra of the three raw materials were in accordance with reported spectra of reference. The values of the initial moisture content of the three raw materials RM1, RM2 and RM3 were 5.5, 9.53 and $8.67 \% \mathrm{w} / \mathrm{w}$, respectively. RM2 exhibited higher moisture content than RM1and RM3 most probably because of its higher surface area available for moisture absorption (Table 1).

The moisture uptake profiles for the three raw materials (RM1-RM3) stored at different conditions exhibited a similar trend (Figure $1 \mathrm{~A}, \mathrm{~B}$ ). RM2 showed the highest moisture uptake rate, followed by RM1 while RM3. This is in agreement with the particle size analysis, as RM2 particles were the 
finest with expectedly the highest surface area available for moisture adsorption. The moisture uptake at $25{ }^{\circ} \mathrm{C}$ was slightly higher as compared with $40^{\circ} \mathrm{C}$ condition. This may be explained by decreased sorption of gases including water vapor attributed to higher kinetic energy at higher temperature (Florence and Attw, 1981). The moisture uptake rate of the three ciprofloxacin raw material started rapidly in the beginning, thereafter, it become slower and a plateau region was attained when the surface of powder become almost saturated with water vapor, which ultimately lead to blockage of surface so prevent further sorption. The rapid moisture uptake in the beginning and then slower might be due to the large surface area available at upper layer of tablet.

Table 1. Raw material characteristics

\begin{tabular}{lccc}
\hline \multicolumn{1}{c}{ Parameter } & (RM1) & (RM2) & RM3 \\
\hline Source & Commercial & Commercial & Developed from RM2 by wet granulation \\
Appearance & Course & Fine & Granular \\
Average particle size $\mu \mathrm{m}$ & 198 & 26 & 730 \\
Hydration state & Monohydrate & Dihydrate & Dihydrate \\
Initial moisture content & $5.5 \% \mathrm{w} / \mathrm{w}$ & $9.53 \% \mathrm{w} / \mathrm{w}$ & $8.67 \% \mathrm{w} / \mathrm{w}$ \\
$(\% \mathrm{w} / \mathrm{w})$ & & & \\
\hline
\end{tabular}

Table 2. Composition of the three formulations

\begin{tabular}{lccc}
\hline Parameters & F1 & F2 & F3 \\
\hline Method of preparation & Slugging & Slugging & Direct compression \\
Raw materials and additives (mg) & RM1 & RM2 & RM3 \\
Ciprofloxacin & 500 & 500 & 500 \\
Croscamellose sodium & 110 & 93.29 & 93.29 \\
Fumed Silica & 4.10 & 4.10 & 4.10 \\
Microcrystalline cellulose & 65 & 27.4 & 27.4 \\
Lactose monohydrate & 20.69 & 20.69 & 20.69 \\
Talc & 20.54 & 20.54 & 20.69 \\
Magnesium stearate & 20.54 & 20.54 & 20.54 \\
PVP k-25 & - & 54.82 & 54.82 \\
\hline
\end{tabular}

Table 3. Compressibility and flowability parameters

\begin{tabular}{cccccccc}
\hline Parameter & Size Particle & $\begin{array}{c}\rho 0 \\
(\mathrm{~g} / \mathrm{mL})\end{array}$ & $\begin{array}{c}\rho 1250 \\
(\mathrm{~g} / \mathrm{mL})\end{array}$ & $\mathrm{Cl}(\%)$ & $\mathrm{HR}$ & $\circ$ & $1250-0$ \\
\hline RM1 & $100-250 \mu \mathrm{m}$ & 0.299 & 0.428 & 30.14 & 1.43 & 39.46 & 0.129 \\
RM2 & $<100 \mu \mathrm{m}$ & 0.630 & 0.842 & 25.17 & 1.34 & 51 & 0.212 \\
RM3 & $>250 \mu \mathrm{m}$ & 0.614 & 0.744 & 17.41 & 1.21 & 22.17 & 0.130 \\
\hline
\end{tabular}

Table 4. Uniformity of weight, Friability and Hardness determination of ciprofloxacin hydrochloride tablets

\begin{tabular}{lcccc}
\hline Formulation & $\begin{array}{c}\text { Uniformity of Weight } \\
(\mathrm{g})\end{array}$ & $\begin{array}{c}\text { Hardness } \\
(\text { Mean Crushing strength) } \\
(\mathrm{Kg} / \mathrm{cm} 2)\end{array}$ & $\begin{array}{c}\text { Sample Friability } \\
(\%)\end{array}$ & $\begin{array}{c}\text { Disintegration Time } \\
\text { (minutes) }\end{array}$ \\
\hline F1 & $0.775 \pm 0.074$ & $6 \pm 0.00$ & $0.200 \pm 0.310$ & $8 \pm 0.020$ \\
F2 & $0.785 \pm 0.060$ & $7.8 \pm 0.5$ & $0.310 \pm 0.100$ & $10 \pm 0.630$ \\
F3 & $0.785 \pm 0.007$ & $5 \pm 1.89$ & $0.200 \pm 0.290$ & $4 \pm 0.466$ \\
\hline
\end{tabular}

Mean \pm S.D, $\mathrm{n}=6$

The dissolution profiles of the raw materials were similar. All the tested raw materials released almost $50 \%$ in 10 min (Figure 1C). The granular RM3 showed the fastest initial dissolution rate, which could be due to the hydrophilic nature of PVP K-25, followed by coarse RM1 and finally the fine RM2. Table 1, show results for particle size analysis of the raw materials. The average particle size was found to be 198, 26 and $730 \mu \mathrm{m}$ for RM1, RM2 and RM3, respectively. This variation had direct effects on the flow and compression properties of the materials. Particle size distribution and bulk density changes affect die filling (Sinka et al., 2004) and compression properties of dry raw materials was agreed with the ibuprofen (Timmins, 1986). 
Free flowing powders have low \%C (<18\%) and low HR $(<1.25)$, and a small angle of repose $(<25)$ (Chateau et al., 2007). In contrast, cohesive, high compressive powders have high \%C $(>20 \%)$.high HR (>1.4) and large angles of repose (Chateau et al., 2007). Data obtained for each granulometrical fraction are shown in (Table 3). The higher differences observed between values of both densities are found in the $<100 \mu \mathrm{m}$ fraction (RM2) indicating the presence of bigger interparticular spaces in comparison with the $>250 \mu \mathrm{m}$ and 100 to $250 \mu \mathrm{m}$ fraction in RM3 and RM1 respectively.
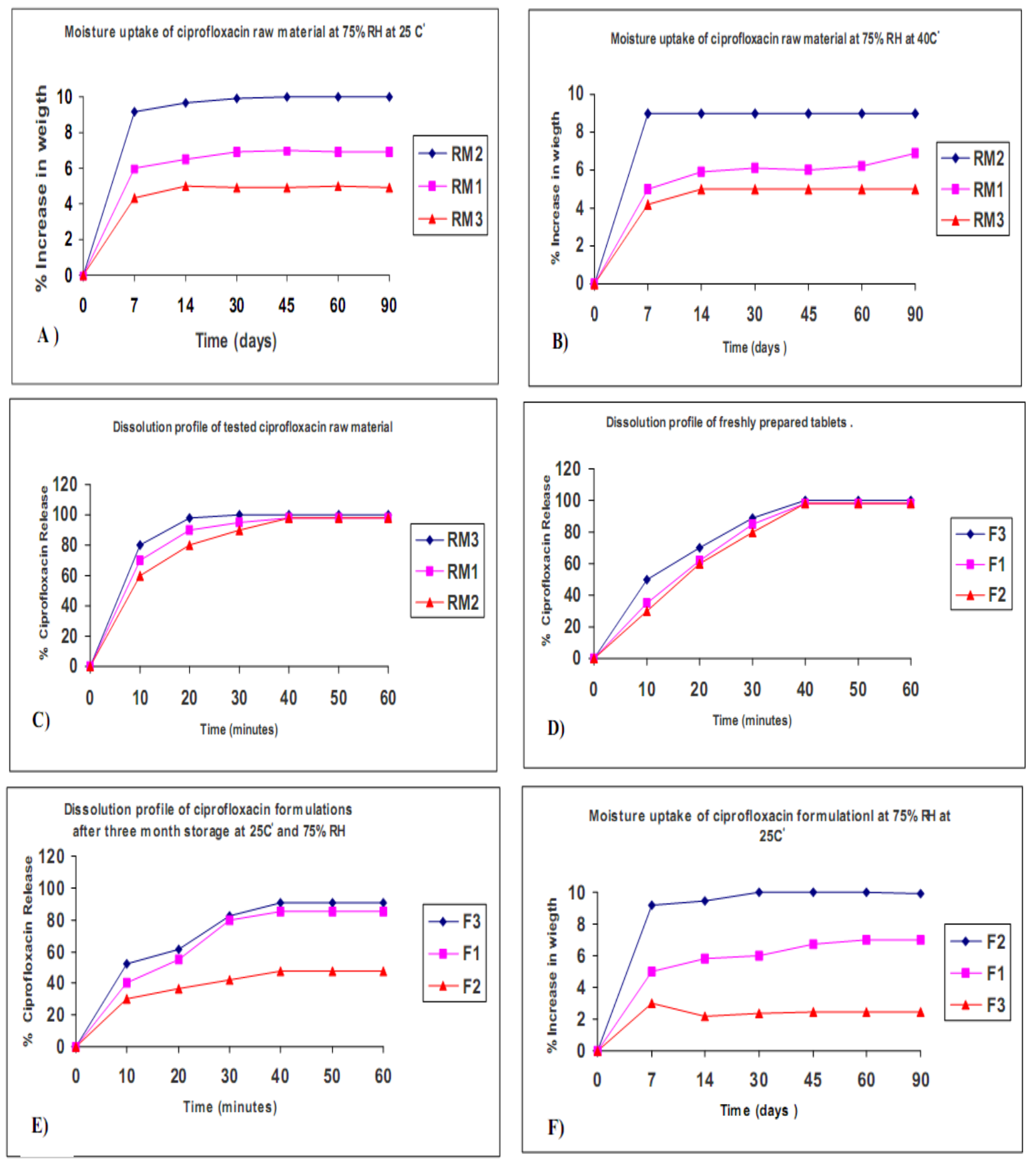


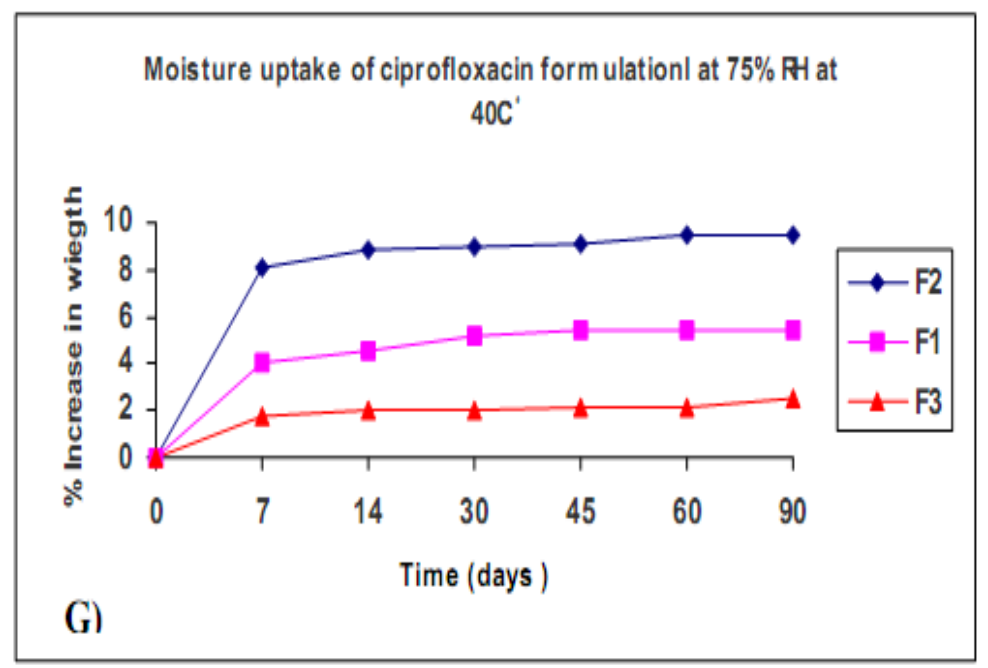

Figure 1. Showing the effect of raw materials on developed Ciprofloxacin tablets on drug release: A \& B) Moisture uptake of ciprofloxacin raw material at $75 \% \mathrm{RH}$ at $250 \mathrm{C}$ and $400 \mathrm{C}, \mathrm{C} \& \mathrm{D})$ dissolution profile of tested ciprofloxacin raw material and freshly prepared tablets E) dissolution profile of ciprofloxacin formulation after 3 month storage at $250 \mathrm{C}, \mathrm{F} \& \mathrm{G})$ Moisture uptake of ciprofloxacin formulation at $75 \% \mathrm{RH}$ at $250 \mathrm{C}$ and $400 \mathrm{C}$.

Angles of repose were 39.46, 51 and $22.17^{\circ}$ for RM1, RM 2 and RM3 respectively (Table 3). The coarse ciprofloxacin RM1 exhibited better flow than the finer raw material RM2. Granular RM3 showed the best flow. As a general guide, powders with angles of repose greater than $50^{\circ}$ have unsatisfactory flow, whereas angles close to $25^{\circ}$ correspond to good flow properties (Staniforth, 1988). According to HR and \%C, the better flowability corresponds to RM3 (>250 $\mu \mathrm{m}$ fraction). Its $\% \mathrm{C}<18 \%$ (Carr's index) indicates good flow (free flowing powders) and its $\mathrm{HR} \approx 1.2$, it can be concluded that both granulometrical fractions $(>250 \mu \mathrm{m}$ and 100-250 $\mu \mathrm{m})$ exhibit adequate rheological properties. All the three ciprofloxacin formulation (F1, F2 and F3) pass the U.S.P friability test. (Table 4). The mean disintegration times of the tablets were 8,10 and 4 min for F1, F2 and F3 tablets, respectively and all of them pass the U.S.P disintegration test (Table 4). The freshly prepared tablets (F1-F3) passed the U.S.P. dissolution test (Figure 1D) as the amounts of ciprofloxacin released were more than $80 \%$ in 30 min. However, F2 tablets exhibited initial slower dissolution, which may be attributed to the effect of slugging and its fine particle size (Florence, 1981; Mazuel, 1991, Wallis et al., 1995). The results of the moisture uptake by the various tablet formulations stored at $25^{\circ} \mathrm{C}$ and $40^{\circ} \mathrm{C}$ at $75 \% \mathrm{RH}$ are shown in Figures $1 \mathrm{~F}, \mathrm{G}$. The $\mathrm{F} 1, \mathrm{~F} 2$ tablets picked up moisture, while F3 tablets showed essentially a desorption phase, which may be explained by evaporation of residual isopropanol (Konsil et al., 2002; Grcic et al., 2003). The rank order for sorption of tablets (F2>F1>F3) was in accordance with the moisture uptake profiles of the powder raw materials. The characteristics of the ciprofloxacin formulations induced different levels of moisture uptake by their respective tablets. The highest level was observed with F2 and to a lesser extent with F1. However, the desorption process occurring with F3 tablets prepared by pregranulation was not noted with RM3. The moisture uptake levels of the tablets stored at $25^{\circ} \mathrm{C}$ were higher than those obtained upon storage at $40^{\circ} \mathrm{C}$, in accordance with those obtained with ciprofloxacin raw material. The profiles in Figures $1 \mathrm{~F}$ and $\mathrm{G}$ indicate that, the increase in moisture uptake of tablet was linear in the initial stage due to the moisture absorption by the outer layers of tablets, followed by slower phase in the deeper layers. A plateau region followed this initial phase after the surfaces of the tablets became saturated with water vapour and no more water vapour could further penetrate the surface. These results agreed with the previous finding (Bertilsson, 1978; Gönül et al., 2000; Çomolu et al., 2005; Chantraine et al. 2007). Freshly prepared F2 tablets passed the USP 25 dissolution test (Figure $1 \mathrm{D}$ ), they failed to pass the test after storage for 3 months at $25{ }^{\circ} \mathrm{C} 75 \% \mathrm{RH}$; the other two formulations ( $\mathrm{F} 1$ and $\mathrm{F} 3$ ) passed the test both when freshly prepared and after three months of storage (Figure $1 \mathrm{E}$ ). The dissolution patterns of tablets were in accordance with their respective raw materials at $25^{\circ} \mathrm{C}$ and $75 \% \mathrm{RH}$, even after storage for the three months. The integrity of ciprofloxacin in stored tablets was assessed by HPLC, which distinguished ciprofloxacin from its degradation product (the ethylene diamine analogue). No 
traces of ethylene diamine analogue could be detected in any of the tested tablets under different storage condition during the whole period of the stability study.

\section{CONCLUSION}

The granular form of ciprofloxacin (RM3) prepared in the present work showed better overall physicomechanical properties compared with RM1 and RM2, including; enhanced flow properties, higher bulk and tapped density , better dissolution profile ,minimal moisture uptake. Deterioration in drug release characteristics was marked in F2 tablets stored under different conditions and resulted in failing the USP 25 dissolution test for ciprofloxacin tablets after 3 month of storage. The results obtained with F3 tablets suggest that the moisture sorption tendency of ciprofloxacin raw material could be controlled by pregranulation with nonaqueous liquid followed by compression which maintained their good performance characteristics when challenged with high temperature and humidity. Although physicochemical preformulation screening is practised universally within the pharmaceutical industry, physicomechanical screening is applied to a lesser extent and often only where a problem exists. For example, a physicomechanical quality control test may be introduced during the early development of a formulation to avoid processing or quality problems, such as flow tests for direct compression. In our research we advise pharmaceutical industry to do physicomechanical screening in each batch production to decrease batch to batch variability and improve quality of production.

\section{REFERENCES}

Bertilsson L. (1978) Clinical pharmacokinetics of carbamazepine. Clin.Pharmacokinet. 3(2): 128143.

Chantraine F, Viana M, Cazalbou S, Brielles N, Monval OM, Pouget C, Branlard P, Rubinstenn G, Chulia D. (2007) From compressibility to structural investigation of sodium dodecyl sulphate- Part 2: A singular behavior under pressure. Powder Techno. 7: 41-50.

Chateau ME, Galet L, Soudais Y, Fages J, Elsevier BV. (2007) Characterisation of the flow behaviour of pharmaceutical powders using a model die-shoe filling system. 173 (1) 59-71.

Florence AT and Attw (1981) Physicochemical Principles of Pharmacy Macmillan Press, USA, pp 203.

Gönül N, Ölçer A, Baykara T, Taygal Ö. (2000) Investigation of in vitro dissolution rates among the batches of the tablets containing flutamide. FABAD J.Pharm.Sci. 25: 11-17.

Grcic J, Perissutti B, Moneghini M, Voinovich D, Martinac A, Jalsenjak I. (2003) Spray-dried carbamazepine loaded chitosan and HPMC microspheres: preparation and characterisation. JPP 55:921-931.

Konsil J, Dechasathian S, Mason D, Stevens R. (2002) Reanalysis of carbamazepine-epoxide pharmacokinetics after multiple dosing of extended release formulation. $J$ Pharm Pharmaceut Sci. 5(2):169-175.

Lide DR. ((2001) CRC Handbook of Chemistry and Physics, pp 15-25, 82nd Ed, CRC Press, San Diego, CA, USA.

Mazuel C. (1991) Ciprofloxacin" in K. Florey, Ed., Analytical Profiles of Drug Substances, vol. 20, Academic Press, Inc., USA, pp 557-600.

Physician's Desk Reference (2001) 55th Ed; pp.1983-1985 Medical Economics Co., Inc., Montvale, NJ, USA,

Sinka LC, Schneiderb R, Cocks ACF. (2004) of the flow properties of powders with special reference to die fill. Int. J. Pharmace. 280 (1-2) 27-38. 
Ali et al., 2009

Staniforth J. (1988) "Powder Flow" in M.E. Aulton Ed., Pharmaceutics, The Science of Dosage Form Design, 2nd Ed, English Language Book Society / Churchill Livingstone, UK, pp 197210.

The United States Pharmacopoeia (2002) 25th Ed., United States Pharmacopeial Convention, Inc., Rochville, USA.

Timmins P, Browning I, Delargy AM, Forrester JW, Sen H (1986) Effect of Active Raw Material Variability on Tablet Production: Physicochemical, Physiocomechanical and Pilot Plant Studies. Drug Dev. Ind. Pharm . 12 (8-9): 1293-1307.

Wallis SC, Charles BG, Gahan LR. (1995) Rapid and economical high-performance liquid chromatographic method for the determination of norfloxacin in serum using a microparticulate C18 guard cartridge. J. Chromatogr. 674 (2): 306-309. 